\title{
Study on the Innovation of Business Model of Full-service Airline
}

\author{
Zheng Xing ${ }^{1, \text { a }}$ \\ ${ }^{1}$ Economics and Management College, CAUC, Tianjin, 300300 \\ ${ }^{a}$ email
}

Keywords: Innovation; Structural equation model; Business model; Full-service Airline

\begin{abstract}
With the rapid development of information technology supported by the Internet, it has deeply influenced the air transport service industry. And the traditional full-service airline is difficult to survive in the Internet era. Through identifying the impact factors of business model innovation, it is found that Internet + and value principle of transport service industry play positive role in business model innovation, based on 400 survey data to build structural equation model.
\end{abstract}

\section{Introduction}

Peter Drucker, the father of modern management, put forward:"Nowadays, the competition of enterprise is not the products, but the business model.” ${ }^{[1]}$ In the air transportation service industry, it could be divided into two types, such as full service airline and low cost airline. For the full service airlines, due to the impact of extensive business model and Internet, they are involved in evil situation.

Although the advantage of full service airline is to provide seamless service, the main source of income is from ticket. In 2015, more than $80 \%$ of revenue of full service airline from Air China, China Eastern Airline and China Southern Airline is from ticket. And the net profit rate is only about $5 \%$. In the air transportation service industry, the homogeneity of product is serious and the price war is universal. Compared to the low cost airline, the competitive of full service airline is weak. In addition, the auxiliary revenue is only $6 \%$. This shows that the service, launched by the full service airline, has not received the favor of passengers and the acceptance of market. In this way, regarding the service as strengths, full service airline is faced with high operating cost and single profit model, which can not survive in the market.

Based on Internet, the information technology has progressed, which end the situation of information asymmetry and promote consumers to the core position. For the air transportation service industry, from design, production, distribution to sales, the aim is to satisfy consumers' needs. However, in the distributed model, over 70\% of passengers for Air China, China Eastern Airline and China Southern Airline are from ticket sales agents, which increases the operating costs. In addition, due to high degree of dependence on distribution and absence of platform, faced with travelers' requirements, it perform slowly and not timely. What's more, with the passenger demand toward individuation and diversification, relying on standardized service, it could not create value.

Under the impact of Internet, traditional business mode of full service airline could not survive. Then, how to design its business model is worth studying, which is helpful to get rid of dilemma and reshape competitive advantage. Based on Internet, the paper employs structural equation model to study the impact mechanism of business model, which provide foundation and support for the construction of business model for all service airline. 


\section{Analysis on the business model of full service airline}

For business model, information is fundamental and important role. Timmers put forward that business model is about the structure of product, service and information, which describes the participants, the potential profit and income of business. ${ }^{[2]} \mathrm{Al}$-Debei regarded that business model is the abstract presentation of business model, by the texts and graphs, to describe core products and services of enterprises. ${ }^{[3]}$ In the Internet era, the big change is information, which imposes deep influence on business model. ${ }^{[4]}$ The information flows in the way of nanosecond speed and non direction, which breaks the traditional business model based on information asymmetry. It also has been confirmed by research. Linder\&Canrell (2000) proposed that business model is about the logic of value creation, which the relevant work for enterprise is surrounded by ${ }^{[5]}$ What's more, by imposing the effect on value creation, the Internet then influences the business model.

For all service airline, relying on air carrier, it could keep developing. And air transport service is long, systematic, comprehensive and complex course. Under the traditional business model, it could not maintain the travelers' experiences. However, with the infiltration of Internet, the information occlusion of air transportation service industry has been broken. With the help of Internet, the creation of business model is not difficult for full service airline. What's more, its trend is integrated services provider.

\section{The business model of all service airline based on structural equation model}

Structural equation model is to study casual relationship in the social science, which is simplified to SEM. ${ }^{[6]}$ SEM is one method of establishing, estimating and testing casual model, which contains latent variables and observed variables, to conduct explored factor analysis, validated factor analysis, path analysis and variance analysis. What's more, it is suitable for processing single index and multiple variables, which could be expressed by three matrix equations.

$$
\begin{aligned}
& \mathrm{x}=\Lambda_{\mathrm{X}} \xi+\delta \\
& \mathrm{y}=\Lambda_{\mathrm{y}} \eta_{+} \varepsilon \\
& \eta=\mathrm{B} \eta_{+} \Gamma \xi+\zeta
\end{aligned}
$$

Among them, the formula (1) and formula (2) belong to measurement model. The formula (3) is structure model. First, $\mathrm{X}$ refers to exogenous observation variables and $\xi$ refers to exogenous latent variables. $\Lambda_{\mathrm{X}}$ expresses the relationship of exogenous latent variables and exogenous observation variables. And $\delta$ is related to error vector of exogenous variables. Second, y refers to endogenous observation variables and $\eta$ refers to endogenous latent variables. $\Lambda_{\mathrm{y}}$ expresses the relationship of endogenous latent variables and endogenous observation variables. $\varepsilon$ is related to error vector of endogenous variables. Third, $B$ and $\Gamma$ represent path coefficients.

Employing SEM, it is helpful to conduct analysis on the business model, which is to deal with complex relationship between variables and improve the situations of variables that could not be measured. Therefore, SEM is a very effective way to study the impact mechanism. 


\section{Theory and hypothesis}

Under the conclusion of research on Internet business model, the article takes the value creation as exogenous variables, Internet + and value principle as endogenous variables. From the perspective of Internet business model, it put forward research hypothesis and the construction of model. The hypothesis is listed from H1 to H6.

H1: Internet + imposes positive effect on the creation of business model

H2: Internet + imposes positive effect on value creation

H3; value principles imposes positive effect on creation of business model

$\mathrm{H} 4$; value principles imposes positive effect on value creation

$\mathrm{H} 5$; value creation imposes positive effect on creation of business model

H6; Internet + imposes positive effect on value principles

The above hypothesis contain the variables of Internet and business model of all service airline (H1、H2、H3、H4) and each other (H5、H6) . The figure 1 expresses its conceptual model.

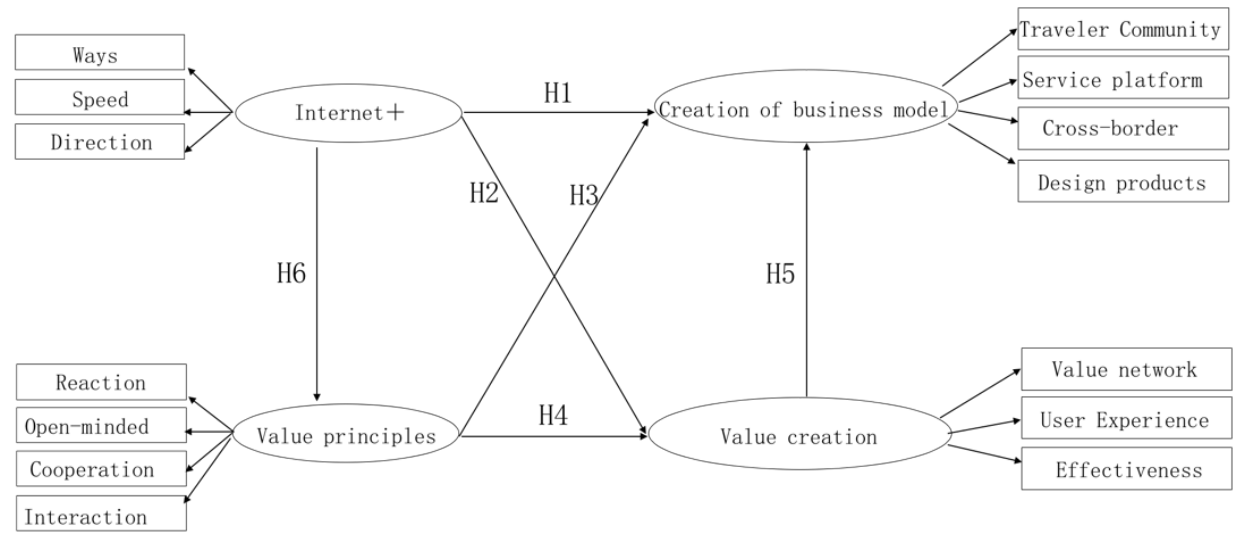

Figure 1. The conceptual model of business model influenced by Internet

The Internet + imposes effect on business, by the ways, speed and direction of information flows. When information changed the previous business form, all activities about business then diversify. First, it takes influences on value principles and value creation. After that, it indirectly takes effect on the creation of business model. On the other hand, under the influence of Internet+, the value principles would change, performance in four aspects. They are reaction, open-minded, cooperation and interaction.

Under the effect of Internet+ and value principles, the value creation has transformed completely, which expressed in logic, format and way. What's more, they all conduct effect on the creation of business model. The trend of its would be based on traveler community. By constructing service platform, it enhances the communication and interaction between all service airline and passengers. For satisfying travelers' demands, full service airline would design products that consumers are in favor of under the situation of platform.

\section{The verification of model}

Considering research object that is all service airline and variables that is relatively professional, the paper adopts the ways of combining field survey and network survey. The cumulative number of questionnaires amounts to 600, which involves business administration of all service airline. The question contains of 15 aspects. Among them, 420 copies are effective and the rate is $70 \%$.

For 420 effective questionnaires, the paper employs SPSS 21.0 to conduct statistical analysis. The value of Cronbach's $\alpha$ represents the situation of reliability analysis. From chart 1 , the 
Cronbach's $\alpha$ of observation variables are over 0.8 , which confirms the questionnaire data that is credible.

Chart.1 Reliability analysis of questionnaire data

\begin{tabular}{|c|c|c|}
\hline Measuroment variables & Numbers & Cronbach' $s$ a \\
\hline Internet+ & 3 & 0.888 \\
\hline Value principles & 4 & 0.881 \\
\hline Value creation & 3 & 0.844 \\
\hline Creation of busincss model & 4 & 0.866 \\
\hline Goncral situation & 14 & 0.868 \\
\hline
\end{tabular}

The validity analysis of questionnaire includes two aspects: content validity and construction validity. Among them, the content of questionnaire has been repeatedly demonstrated by industry experts. In detail, the construction validity is reflected by the value of KMO and Bartley sphere test. When the value of KMO is over 0.7 and the statistics value of Bartley sphere test is amounted to 0.000 , it expresses that the construction validity of questionnaire meets the requirements. From chart 2 , the results are listed.

Chart.2 Validity analysis of questionnaire data

\begin{tabular}{|c|c|c|}
\hline Measurement variables & KM0 & Bartley sphere test \\
\hline Internet + & 0.824 & Chi square:369.490, freedom: $3, \mathrm{P}<0$ \\
\hline Value principles & 0.812 & Chi square: 1031.199 , freedom:4, $\mathrm{P}<0$ \\
\hline Value creation & 0.712 & Chi square: 697.602 , freedom: $3, \mathrm{P}<0$ \\
\hline Creation of business model & 0.802 & Chi square: 563.198 , freedom: $4, \mathrm{P}<0$ \\
\hline General situation & 0.829 & Chi square: 4459. 154, freedom: $6, \mathrm{P}<0$ \\
\hline
\end{tabular}

Figure 2 is a standardized structural equation model constructed by LISREL8.7, based on the collected data.

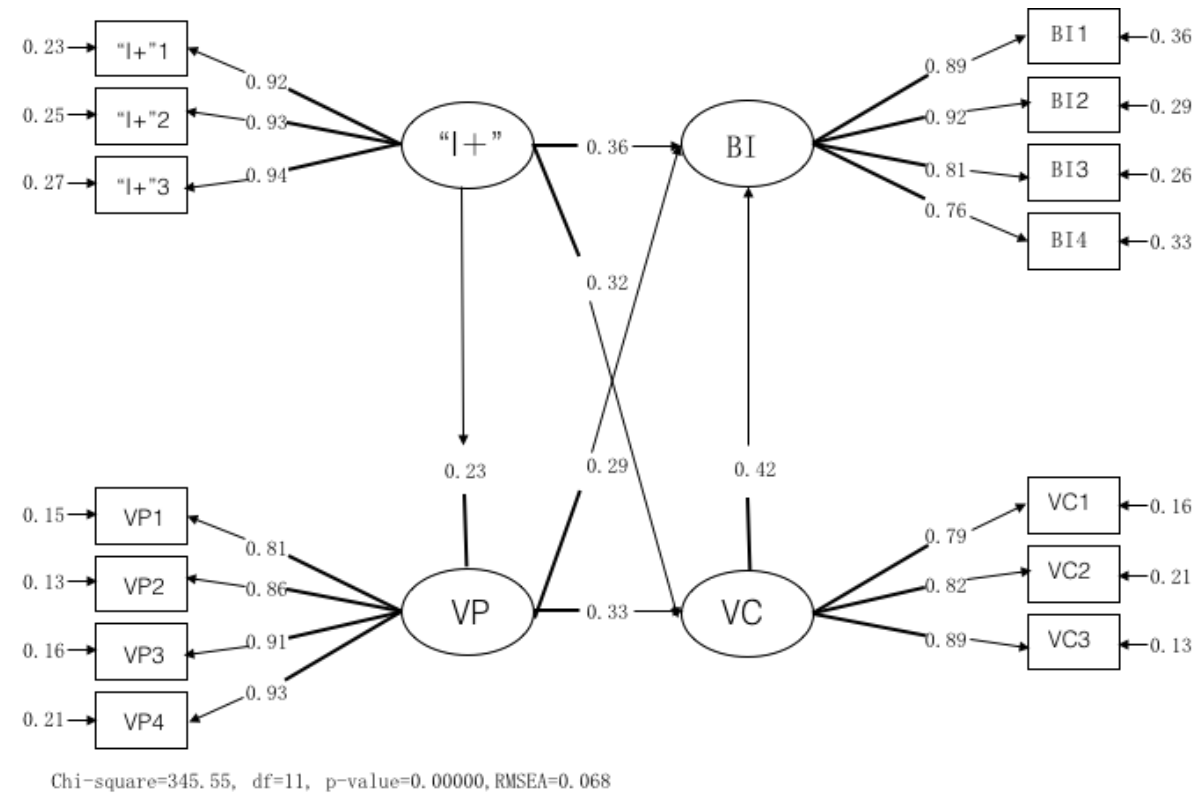

Fig.2 Standard solution of influencial mechanism model on business Model of full-service airline

Through standardized effect, the factor loading of four measurement items of Internet + is respectively $0.92,0.93,0.94$ and 0.89 . The factor loading of value principle is respectively 0.81 , 0.86, 0.91 and 0.93 . Third, the factor loading of value creation is respectively $0.79,0.82$ and 0.89 . 
Fourth, the factor loading of creation of business model is respectively $0.89,0.92,0.81$ and 0.76 . All the factor loading of variables is among $0.76-0.94$, which is over 0.5 . Then, all the measurement items could explain the meaning of latent variables.

The path coefficients among latent variables were successfully tested by the testation of $T$ value. And the path coefficient of two endogenous latent variables is 0.42 , which confirms the important path relationship between value creation and the creation of business model. The path coefficient of two exogenous latent variables is 0.23 , which confirms the important path relationship between Internet + and value creation. Therefore, none of path could be eliminated. In addition, the fitting situation of model could be mirrored by fit index from chart 3. From chart 4, all the hypothesis could be qualified.

Chart 3 Fitted index of model for the business Model of full-service airline

\begin{tabular}{|c|c|c|c|c|c|c|c|c|c|c|c|}
\hline & \multicolumn{4}{|c|}{ Absoulute } & \multicolumn{4}{c|}{ Relative } & \multicolumn{2}{c|}{ Simple } \\
\cline { 2 - 14 } Fit index & GFI & AGFI & RUSEA & SRNR & NFI & NNFI & CFI & IFI & RFI & PNFI & PGFI \\
\hline Standard & $>0.90$ & $>0.90$ & $<0.06$ & $<0.08$ & $>0.90$ & $>0.90$ & $>0.90$ & $>0.90$ & $>0.90$ & $>0.50$ & $>0.50$ \\
\hline Model & 0.92 & 0.89 & 0.068 & 0.04 & 0.96 & 0.97 & 0.97 & 0.97 & 0.95 & 0.78 & 0.67 \\
\hline
\end{tabular}

Tab.4 Verification of research hypothesis

\begin{tabular}{|c|c|}
\hline Hypothesis & Situation \\
\hline H1: Internet + imposes positive effect on the creation of business model & Adopted \\
\hline H2: Internet + imposes positive effect on value creation & Adopted \\
\hline H3: value principles imposes positive effect on creation of business model & Adopted \\
\hline H4: value principles imposes positive effect on value creation & Adopted \\
\hline H5: value creation imposes positive effect on creation of business model & Adopted \\
\hline H6: Internet + imposes positive effect on value principles & Adopted \\
\hline
\end{tabular}

\section{Conclusion}

Under the analysis of business model influenced by Internet + , this paper constructs SEM model and conducts empirical research. From the analysis of survey data, it verifies the validity of model and improve the theoretical model. Based on the above analysis, the following conclusions are drawn:

First, the Internet imposes an impact on the business model of full service airline. The effect of different elements is not the same. In addition, by a significant role in the value principles, the Internet thus affects the creation of business model.

Second, value creation is the core of the creation of business model. Under the function of the Internet, the mode, logic of value creation is changed. And the direction of business model of all service airline is affected.

Third, in the Internet era, the production and operation of full service airline can not be separated from the service-sensitive traveler community, which drives the creation of business model of full service airlines.

\section{References}

[1] Webster F E. Marketing IS management: The wisdom of Peter Drucker[J]. Journal of the Academy of Marketing Science, 2008, 37(1):20-27.

[2] Timmers P. Business models for electronic markets [J]. Electronic markets, 1998, 8(2): 3-8.

[3] Al-Debei M M, Avison D. Developing a unified framework of the business model concept[J]. 
European Journal of Information Systems, 2010, 19(3):359-376.

[4] Teece D J. Business Models, Business Strategy and Innovation[J]. Long Range Planning, 2010, 43(2-3):172-194.

[5] Shafer S M, Smith H J, Linder J C. The power of business models [J]. Business horizons, 2005, 48(3): 199-207.

[6] Ringle C M, Sarstedt M, Straub D W. Editor's comments: a critical look at the use of PLS-SEM in MIS quarterly[J]. Mis Quarterly, 2012, 36(1):iii-xiv. 